\title{
Successful Aging: Indigenous Men Aging in a Good Way with HIV/AIDS
}

\author{
Chaneesa Ryan, ${ }^{1}$ Randy Jackson, ${ }^{1,2}$ Chelsea Gabel, 1,3 Alexandra King, ${ }^{4}$ Renee Masching, ${ }^{5}$ and \\ Elder Cliff Thomas 5
}

\begin{abstract}
RÉSUMÉ
Les traitements associés au VIH ayant progressé au cours des 30 dernières années, le nombre de personnes âgées vivant avec le VIH s'est accru. Ce phénomène est particulièrement important chez les peuples autochtones du Canada, compte tenu de la surreprésentation chronique de cette population dans les diagnostics de VIH. Toutefois, peu de données sont disponibles sur l'expérience des Autochtones séropositifs plus âgés. Une approche fondée sur les forces a permis d'explorer comment les hommes autochtones plus âgés vivant avec le VIH conçoivent le vieillissement réussi. La recherche a été menée en partenariat avec le Réseau canadien autochtone sur le sida. Des hommes des Premières nations, Inuits et Métis, âgés de 43 à 63 ans et séropositifs depuis 10 à 29 ans, ont participé à des groupes de discussion et à des entrevues. Une approche analytique ouverte a été utilisée pour étudier le contenu des transcriptions. Les codes ont été développés en collaboration, par un processus inductif et itératif. Nous présentons l'analyse des points communs entre les groupes autochtones, ainsi que nos réflexions sur l'application du modèle de vieillissement réussi aux hommes autochtones plus âgés ayant le VIH.
\end{abstract}

\section{ABSTRACT}

Because of advances in treatment over the past 30 years, the number of older people living with HIV is growing. This is important for Indigenous Peoples in Canada, given their continuing over-representation in HIV diagnoses. However, little is known about the experiences of older, HIV-positive Indigenous Peoples. Taking a strength-based approach, this research explored how older Indigenous men with HIV conceptualize successful aging. Research was conducted in partnership with the Canadian Aboriginal AIDS Network. First Nations, Inuit, and Métis men, ranging in age from 43 to 63 years who had been HIV positive for 10-29 years participated in sharing circles and interviews. An open analytic approach was used to explore the content of transcripts, and codes were collaboratively developed through an inductive and iterative process. From our analysis of commonalities across Indigenous groups, we offer our insights on the application of the successful aging model to Indigenous men aging with HIV.

\section{OJIBWE ABSTRACT}

Maanda agaazhi maajiishkaamgak ezhi naagdewenjgaadeg woshme agwa nsimdana shi bboon, mnik eyaajig gechi piitzijig bemaadzijig eyaamwaad HIV maajiishkamgad. Kitchi piitendaagwad maanda gwanda anishinabek maampii Canada maanda gonaa aapaji baatiinwaad enaapinewaad HIV. Aanwi adash, bangii gakenjgaade ezhi gakendmowaad gwanda gechi piitzijig agaa mkigaazwaad aakoziwaad. Nikaazan mshkoowaadziwin zhi gnoowaamjigaadeg, maanda nanaandowi-gikenjigewin agii dakenjgaaade gwanda getchi piitzijig Anishinaabe ninwok eyaamjig HIV inenmoowaad kitchi piitziwin mina maadziwin. Nanaandowi-gikenjigewin zhichgaade wiidnakiindwaad Canadian Aboriginal AIDS Network, Anishinaabek, Eshkiimewi, miinwaa Wiisaakode ninwok niiwin shi niswi apiinish ngoodwaasmidna epiitzijig agaa gagishkaagwaad aakoziwin mdaaswi apiinish mdaaswi shi zhaangsa biboon wiijiewok maamwi gaataadbing miinwaa gakwedwewin. E'baakisin n'dakenjgewin ezhi gnoowaamjigaadeg maanda agii nikaaznaa'aa awii gnoowaamjigaadeg zhibiiganan miinwaa mzinbiiganan agii maamwi zhichgaadenoon aanji ikidon miinwaa bgamwijgaadeg. Onji iagii ndakendmaang naasaab eyaawong aazhawi Anishiinaabeg ndo miigwenaanin nistatominaanan awii nikaazan mina kitchi piitzin mzinbiigan gwanda Nishinaabe ninwok e'gagiishkaagwaad HIV.

\section{MICHIF ABSTRACT}

Ooshchi ishihtewiin aen tretmaan disseu li paassii 30 l'aanii, ahkikin aen noombr ooshchi vyeu li moond kaa pimatchihoot avek HIV. Ooma maawachi aenportaan poor Indigenous li moond aan daan Canada tapitow maashkooch ishpii ayiwaakpiihkishkwaytakwun aan daan HIV kaa ishaayaahk. Maaka, namoo wiiya mishtahi kaykway kishkayhtakwun ooshchi ay-ishpayihk vyeu, saartayn Indigenous li moond. Kaa ootinamahk la fors-taanishi itayhtamun payyamakun, ooma aen natoonikaywiin kaakway ki-miishkoopitum taanishishi vyeu Indigenous lii zomm avek HIV conceptualize nawut aen vyeu laazh. Aen natoonikaywiin kii maachihtaawuk aan daan wiichiwew avek enn Canadian Aboriginal AIDS Network. Niikaan Naysoon, Inuit miina Michif lii zomm, kaa tapipooynayht ooshchi 43 ishi 63 kaa ki-saartayn poor 10 ishi 29 l'aanii ihtaakoo aan daan wiichihiwayhk aen roon miina piikishkwayhewiin. Tawow ahkamayihtumowiin ta aen kishkishomiwahk ki apaatun kaakway ta miishkoopitum aen ayshpiishchaak ooshchi aen liivr mina aen ishi tootamihk ki wiichihiwayhk kiishihtow shaapoo niikaan miina kiihtwaam ishi ayitootamihk. Ooshchi niiyanaan ooma kishkayhtakwun aen toot lii moond lootr bor Indigenous mamaowwi nakishkatoohwuk niiyanaan va oofayr nishtohtamahkiwiin disseu aen kashkihtanan ta apaachihtayahk aen vyeu laazh mwayshchi Indigenous lii zomm aen vyeu laazh avek HIV. 


\section{INUKTITUT ABSTRACT}

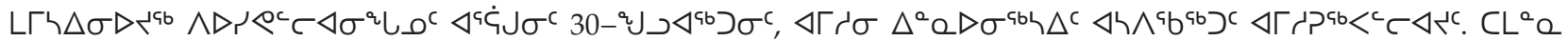

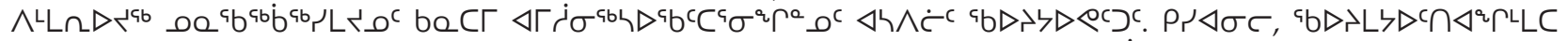

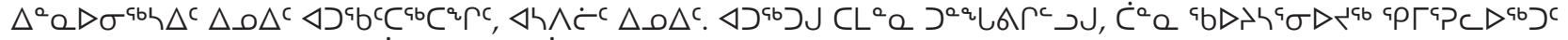

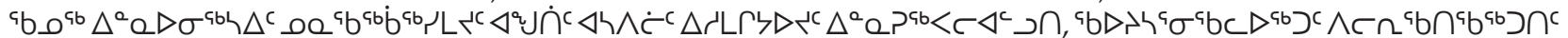

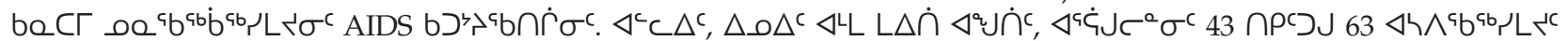

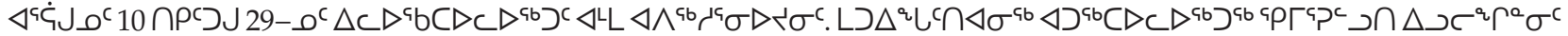

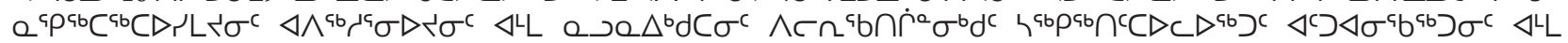

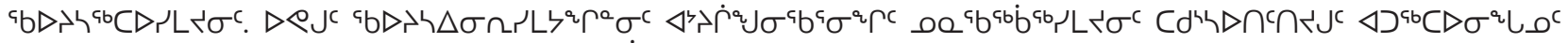

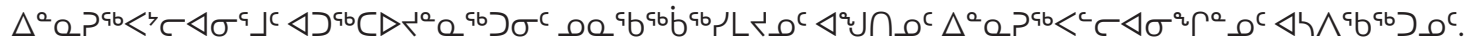

1 Department of Health, Aging, and Society and McMaster University, Hamilton, Ontario.

2 Department of Social Work, McMaster University, Hamilton, Ontario.

3 Indigenous Studies Program, McMaster University, Hamilton, Ontario.

4 Department of Indigenous Health, University of Saskatchewan, Saskatoon, Saskatchewan.

5 Canadian Aboriginal AIDS Network, Dartmouth, Nova Scotia.

* The Canadian Institute of Health Research Institute of Aboriginal People's Health funded this research. We acknowledge members of the Canadian Aboriginal AIDS Network for sharing their stories and wisdom with us. Additionally, we thank the Elders who were involved in this project. We give special thanks to the late Elder Cliff Thomas for his support throughout the duration of this project; his kindness, wisdom, humor, and friendship were invaluable.

Manuscript received: / manuscrit reçu : 02/01/18

Manuscript accepted: / manuscrit accepté : 16/05/19

Mots-clés : vieillissement, hommes autochtones, savoir autochtone, VIH/sida, vieillissement réussi, mieux-être, recherche participative communautaire

Keywords: aging, Indigenous men, Indigenous knowledge, HIV/AIDS, successful aging, wellness, community-based participatory research

La correspondance et les demandes de tirés-à-part doivent être adressées à : / Correspondence and requests for offprints should be sent to:

Chaneesa Ryan, MA

McMaster University

1280 Main St. West

Hamilton, ON L8S 4L8

Canada

(cryan@nwac.ca)

\section{Introduction}

HIV is an infectious virus, which has shifted with advances in treatment from being primarily fatal to being a more manageable, chronic condition (Cahill \& Valadéz, 2013). This means that HIV is no longer a death sentence, and people are living longer, healthier lives. This phenomenon has been described as the "greying of the HIV / AIDS epidemic" (Beuthin, Bruce, \& Shields, 2015; Nevedal \& Sankar, 2015). Consequently, older people with HIV ( $\geq 50$ years of age) are the forerunners of this phenomenon and we have much to learn with them. Although the HIV positive Indigenous population is younger than their non-Indigenous counterparts, 69.3\% of positive Indigenous People are 30-49 years old (Public Health Agency of Canada, 2014), which means that over the next two decades, the percentage of older ( $\geq 50$ years of age) Indigenous Peoples living with HIV/AIDS is going to increase rapidly. Despite significant increases in life expectancy for individuals living with HIV, it is important to consider that Indigenous People with HIV continue to experience higher rates of mortality than nonIndigenous Canadians (Benoit et al., 2017). Indigenous means "native to the area"; in Canada, there are three recognized groups of Indigenous Peoples: First Nations, Inuit, and Métis. In Canada, the Constitution Act of 1982 refers to these three groups as "Aboriginal Peoples". However, there is a growing awareness of the importance of moving away from government-imposed language to self-declared language. This shift in language aligns well with a de-colonizing approach and "Indigenous Peoples" will therefore be used in place of "Aboriginal Peoples".

Additionally, there is a whole generation of young people born with HIV who are aging into adulthood and growing up with the virus. Their experience of aging with HIV is unique and complex and is not included in this analysis of Indigenous men aging with HIV. This study focuses on those who are dealing with aging in the "second half" of life and with the impact of 
HIV on an aging body, mentally, physically, spiritually, and emotionally. There are even more questions related to living with and aging with HIV over long periods of time, regardless of chronological age.

Members of the Canadian Aboriginal AIDS Network (CAAN) have expressed concern about a lack of culturally mediated knowledge surrounding aging with HIV. Discrepancies in respect to notions of health and disease coupled with the relatively new emergence of aging with HIV has resulted in a lack of culturally resonant information regarding successful aging for Indigenous Peoples with HIV. Because culture greatly impacts the experience of disease (Cammer, 2006) lacking an understanding of the cultural beliefs that shape the experiences of Indigenous Peoples aging with HIV makes it very difficult to provide culturally appropriate care for this population.

Although there is a vast diversity among Indigenous languages, cultures, values, traditions, and ceremonies, Indigenous Peoples of Canada share a similar worldview, which shapes their ways of life (King, Smith, \& Gracey, 2009). The fact that this research focuses on Indigenous Peoples with HIV, rather than focusing on one of the three Indigenous groups in Canada: First Nations, Inuit, or Métis, or further, a specific nation or even community, is by no means a way to try to generalize and homogenize this population. Similarly, this research focuses on the experiences of men instead of men and women, because of the recognition that men and women experience both aging and living with HIV differently. This research is about honouring the heterogeneity of Indigenous Peoples in this country while exploring common ideas around successful aging from a culturally resonant approach. This objective is rooted in the awareness of the need to include Indigenous knowledges when providing care for Indigenous Peoples (Peltier et al., 2013). Considering the vast diversity within and among First Nations, Inuit, and Métis peoples, languages, cultures, traditions, and beliefs, we assert that proposing a singular Indigenous model of successful aging is highly complex and potentially harmful (Peltier et al., 2013). In recognition of this diversity, we offer our insights on the applicability or rather, inapplicability of the successful aging framework for Indigenous men aging with HIV.

\section{Indigenous Health}

From an Indigenous world-view, disease is understood and approached in a very different manner from that of a Western world-view (King et al., 2009). “The clashing of worldviews between the Western content-oriented, linear, and empirical worldview, and the First Nations process-oriented, nonlinear, and wholistic worldview may explain the discrepancies in perceptions regarding time and the nature of health" (Hughes, 2006, p.11). Western, "allopathic" approaches to health typically view health from the predominant, biomedical model, which characterizes health as the absence of disease. Epidemiological approaches that target individual behavioural interventions may be successful in nonIndigenous populations. However, an epidemiological approach is not congruent with Indigenous epistemologies. Douglas (2013) explains that Indigenous epistemology sees the world as a unified whole; it values the collective over the individual. An epidemiological approach does not provide the context that is necessary to gain a more comprehensive picture of health and illness. For many Indigenous People, health is far broader and holistic. Health from an Indigenous perspective considers spiritual, emotional, mental, and physical well-being on not only an individual level but also a community level. Therefore, a more holistic approach to health that incorporates social, cultural, historical, political, and economic contexts needs to be considered when working with Indigenous Peoples.

Ultimately, conventional scientific approaches are not congruent with Indigenous bodies of knowledge and epistemologies. Therefore, they will fall short in addressing the epidemic of HIV within this population. Many Indigenous Peoples do not reject biomedicine; they too want the benefits that new health technologies offer, they just do not want the epistemology that accompanies it (Douglas, 2013). Therefore, epistemological accommodation, which Douglas (2013) describes as a process in which Indigenous patients and nonIndigenous health care providers accommodate and respect each other's world-views, is needed. Epistemological accommodation is necessary for the provision of culturally safe care. The knowledge of health scientists and of Indigenous Peoples needs to be considered equally valuable and relevant to the problem. Without this recognition, Indigenous health research risks further perpetuating the cultural hegemony of Western knowledge over Indigenous knowledge. In addition to the need for epistemological accommodation in HIV programs and services for Indigenous men, approaches need to be relational. Wilson (2008) argues that researchers who intend to conduct research with and within Indigenous communities must engage in a relational research process, one that is built on Indigenous concepts of relationality. The intent is to create decolonial spaces to improve relationships between Indigenous and non-Indigenous communities and peoples (Wilson, 2008). Henry and colleagues draw on Kirkness and Barnhardt's 4Rs - respect, relevance, reciprocity, and responsibility - for researchers. They suggest that "Reflexivity is central to the process, since at all stages, researchers and their partners must become consciously aware of their cultural capital and its impact on the research process. It is through this process, or relational accountability, that agency can be 
acknowledged and research methods can be modified to fit the social realities of the participants and community" (Henry, Tait, \& STR8 UP, 2016, p. 184). Therefore, emphasis needs to be placed on relational connections within supportive environments where health and well-being can be achieved (Peltier et al., 2013) and Indigenous men with HIV can age successfully.

\section{HIV and Aging}

Indigenous Peoples in Canada experience disproportionate rates of chronic and infectious diseases; higher rates of substance abuse, suicide, and addictions; and an overall lower life expectancy than their non-Indigenous Canadian counterparts (Adelson, 2005). Indigenous Peoples in Canada are three and a half times more likely to acquire HIV than non-Indigenous Canadians (Public Health Agency of Canada, 2014). The Public Health Agency of Canada (2014) highlights Indigenous Peoples as a unique segment of the nations' concentrated HIV epidemic because of their younger age at time of infection and the significantly higher number of infections attributed to the exposure category of injection drug use. In response, the Public Health Agency of Canada (2014) highlights the need for culturally relevant interventions for prevention, treatment, care, and support with this population.

Even though age 65 commonly signifies senior status, for the purpose of this research, an older adult refers to someone over the age of 50. Many organizations and health care professionals offer services for seniors to Indigenous People younger than 65 because of their shorter life expectancy and their earlier onset of chronic conditions in comparison with other Canadians (Health Council of Canada, 2013). Furthermore, age 50 is commonly used in the HIV and aging literature to denote old age (Brennan, Emlet, Brennenstuhl, Rueda, \& Ontario HIV Treatment Network Cohort Study Research Team and Staff, 2013). This change in the chronological categorization of old age is partially attributed to the beginning of the epidemic when HIV was viewed as a death sentence. Additionally, it is commonly believed that HIV causes premature aging (Deeks \& Phillips, 2009). When referring to older Indigenous Peoples it is important to recognize the distinction between seniors and Elders. Although terms to refer to older adults such as seniors and elders are often used interchangeably, First Nations, Inuit, and Métis use the term Elder to recognize someone who holds cultural and spiritual knowledge. To distinguish between the two, Elder is capitalized to indicate honour or title. Therefore, the term Elder cannot be used when referring to all older Indigenous People, as it does not refer to age.

The "greying of the epidemic" can be attributed to the advent of antiretroviral therapy, which means that people are living longer lives and are now aging into their 50s, and less so to the growing incidences of HIV diagnoses in individuals over the age of 50 (Balderson et al., 2013). The older adult HIV positive population is composed of three groups: (1) people who have been HIV positive for many years, and who are now over 50 years of age, (2) people over 50 who have recently acquired and been diagnosed with HIV, and (3) people over 50 receiving a late diagnosis, but who had acquired HIV years before. Understandably, each group will have their own set of unique issues inherent to aging with HIV. Issues range from their diagnosis, ability to respond to treatment, disease and symptom management, co-morbidities, mortality, and the ways in which service providers respond to their unique needs. Ellman, Sexton, Warshafsky, Sobieszczyk, \& Morrison (2014) have also identified that there are greater racial and ethnic disparities in HIV diagnoses among those 50 years of age and older. Although the literature on HIV / AIDS and aging is growing, the literature primarily focuses on the biomedical aspects of aging with HIV / AIDS. Consequently, there is limited information on the social aspects of aging with HIV / AIDS (Roger, Mignone, \& Kirkland, 2013; Sankar, Nevedal, Neufeld, Berry, \& Luborsky, 2011; Vance, Struzick, \& Masten, 2008). Beuthin et al. (2015) highlight the fact that, "the day-to-day experiences, realities, and challenges of affected individuals remain largely invisible" (p.1). Given the over-representation of the Indigenous population among people living with HIV, and the current demographic trends of this population, it is alarming that there is no literature on Indigenous Peoples' experiences of aging with HIV.

\section{Successful Aging}

Although there is no universal definition of successful aging, the MacArthur Network on Successful Aging, launched in 1984, operationalized three criteria of successful aging: (1) freedom from disease and disability, (2) high cognitive and physical functioning, and (3) active engagement with life (Martin et al., 2014). These criteria became the basis for the successful aging framework developed by Rowe and Khan (1997), which remains the most widely used conceptual framework in social gerontology today. This framework is testable by assessing older adult's ability to meet each criterion, thus being labeled as "successfully aging" (Martin et al., 2014). Whereas this framework is the most widely used, it is not without controversy and criticism. Social gerontologist Matilda Riley was one of the first to critique Rowe and Kahn's model in a 1998 letter to the editor of the Gerontologist, calling the model "seriously incomplete" given its fixation on individual success and its absence for the consideration of structural and social factors that impact aging (as cited in Martinson \& 
Berridge, 2015, p. 59). Liang and Luo (2012) highlight the irony of the dominance of the successful aging framework, given that it is a discourse based on empirical data collected in the United States, yet is continuously applied to many outside cultures without further reflection. Additionally, we add our own critique of the Rowe and Kahn model of successful aging as potential ableism, with its emphasis on the biology of individuals. The Rowe and Kahn model also excludes those living with HIV, ignoring the variety of ways that people living with HIV successfully adapt to aging with a chronic and disabling illness.

Although the cultural bias in the Rowe and Kahn model of successful aging is recognized and its applicability to non-Western cultures is questioned, there is a lack of dialogue on the successful aging framework's applicability to Indigenous cultures. We would also argue that given the focus on cognitive and physical ability, this model also has a biomedical bias and is ableist in its orientation. We do know that successful aging models are value laden, and given the epistemological and ontological differences between Western and Indigenous cultures, it is easy to see how models of successful aging would not be congruent with Indigenous perceptions of what it means to age successfully. For example, traditional successful aging models have been described as creating a "disharmony between body and mind" (Liang \& Luo, 2012, p. 4), which is very problematic given that in Indigenous understandings of health and wellness, the body and mind cannot be separated. Indigenous notions of health and wellness and, alternatively, disease, are understood and viewed differently from how they are viewed according to a Western world-view (King et al., 2009). Therefore, in ways aligned with a study commissioned by the United Nations' Permanent Forum on Indigenous Issues (2013), the meaningful inclusion of Indigenous Peoples living with HIV are needed to suggest, create, or recommend an Indigenous model of successful aging. A more holistic and nuanced understanding of how Indigenous Peoples living with HIV understand successful aging is needed to better respond to the unique needs of this population.

\section{Methods}

This project was conceived of from the community through a joint dialogue between members of CAAN and the research team. CAAN is a national nongovernmental organization dedicated to providing support and advocacy for Indigenous People living with and affected by HIV / AIDS regardless of where they reside. CAAN members, both Indigenous People and health and social service providers, have expressed concern about a perceived lack of culturally mediated responses to living with HIV. To address their concerns, a community-based participatory research (CBPR) project was formed. A CBPR research design is central to an Indigenous methodological approach. This is because a CBPR project involves full participation of the community in shaping the research question, design, methods, analysis, interpretation, and dissemination (Lavallée, 2009). This kind of approach is particularly important given the history of research involving Indigenous Peoples in Canada. The Indigenous scholar Linda Tuhiwai Smith has stated: "The word itself, 'research' is probably one of the dirtiest words in the Indigenous world's vocabulary... scientific research is implicated in the worst excesses of colonialism and remains a powerful remembered history for many of the world's colonized peoples" (Smith, 1999, p. 1).

In addition to the importance of involving the community throughout all phases of the research process, research with Indigenous populations is optimized by utilizing Indigenous knowledges and de-colonizing methodologies. In accordance with Lavallée's suggestion, this research respects "the core values, beliefs, and healing practices of the Indigenous community... throughout the research process" (Lavallée, 2009, p. 23). This can be demonstrated through the research team's commitment to incorporating ceremony and following cultural protocols throughout the research process as demonstrated through: (1) the adaptation of focus groups to sharing circles, (2) the inclusion of Elders in the research process, (3) opening sharing circles with a prayer and a smudge, led by an Elder, (4) the offering of tobacco to participants at the start of each sharing circle and interview, and (5) the application of TwoEyed Seeing principles, through an approach to research that embraces Indigenous knowledges and Western knowledge. Mi'kmaw Elder Albert Marshall describes Two-Eyed Seeing as having the ability "To see from one eye with the strengths of Indigenous ways of knowing, and to see from the other eye with the strengths of Western ways of knowing, and to use both of these eyes together" (Bartlett, Marshall, \& Marshall, 2012, p. 335). Peltier (2018) discusses her application of the Two-Eyed Seeing principle in her exploration of the potential benefits, challenges, and contributions of Indigenous healing to cancer care and Mino-Bimaadiziwin (an understanding of wellness) for the Anishinaabe people of Manitoulin Island, Ontario, Canada. Peltier examines the metaphorical Euro-Western knowledge eye, and the participatory action research (PAR) component of the research as a way to produce actionoriented findings intended to improve the situation for community members (i.e., promoting agency in accessing plural systems of care, both Indigenous healing and Western medicine). Peltier also draws on the Indigenous knowledge eye, Anishinaabe-Gikendaasowin (Anishinaabe knowledge), which allows the collective story to be presented within a meaningful context for Indigenous 
Peoples and fosters a research process that is culturally safe (Peltier, 2018, p.10). Thus, our research blends Indigenous knowledges and methods (the inclusion of ceremony, Indigenous protocols, and sharing circles) and Western methods (semi-structured interviews and a literature review) to inform this project and collect data. Two-Eyed Seeing was also reflected in knowledge mobilization for both the academic and Indigenous communities. Findings from this research were presented at various academic conferences and submitted for publication to reach the academic community. In order to reach participants of the research and the Indigenous HIV communities at large, findings were shared with participants in the research through member checking and a summary report, and a workshop on successful aging was presented at CAAN's Bi-Annual Wise Practices VI Gathering and the Annual Skills Building Event. Sharing circles highlight the continuing and central importance of oral tradition and storytelling for Indigenous People and provide a cultural signal to Indigenous participants that the process is premised on egalitarian, supportive, non-confrontational values meant to solicit collective agreements (Rothe, Ozegovic, \& Carroll, 2009). Lavallée (2009) describes how sharing circles, although similar to focus groups, differ because of the sacred meaning they hold in many Indigenous cultures, more specifically First Nations, because of their ability to facilitate growth and transformation bases for those who participate. Furthermore, "sharing circles use a healing method in which all participants (including the facilitator) are viewed as equal and information, spirituality, and emotionality are shared, a method that is familiar and comforting for some Aboriginal participants in Canada who have this knowledge of this practice" (Lavallée, 2009, p.28). Like focus groups, a main advantage to sharing circles is the ability to redress the traditional power imbalances between the research participants and the researcher, because collectively, a group may be able to wield more control over the research than a single participant could (Saks \& Allsop, 2007). The inclusion of an Elder in the sharing circle is also a way to redress these power imbalances and to encourage a more culturally resonant and supportive environment for participants. Tobacco ties (tobacco placed in a cloth bundle and smudged by an Elder) are offered to participants as tobacco is recognized as a sacred plant by many Indigenous Peoples. Although the offering of tobacco is often given to Elders in exchange for their knowledge, this protocol can be extended to any person when seeking knowledge. Furthermore, the offering of tobacco in this way is meant to signify the researchers' intentions to use participants' stories in a good way.

Semi-structured interviews were conducted with two participants who were not able to attend the planned sharing circles or were not comfortable in doing so. Although the research team had not initially planned on conducting interviews, the team felt that it was important to be flexible and inclusive in our research approach. This flexible, non-linear approach to the research is characteristic of Indigenous de-colonizing methodologies. Perhaps in a strictly traditional, Western academic approach, this flexibility would be frowned upon. Even further, it might be viewed as a methodological weakness. But given that Indigenous knowledges are fluid and experiential, this flexible approach to the research offered a way to respect and honour cultural protocols and knowledge. To accommodate these participants, the sharing circle questions were used as a guide.

Our sample consisted of CAAN's Wise Practices V conference delegates. This means that participants represented a select group of Indigenous People, who were all open about their HIV positive status, at least within the CAAN community. Although the conference took place in Vancouver, British Colombia, CAAN is a national organization, so conference delegates, and, therefore, participants, represented a diverse sample of Indigenous Peoples from across Canada. The sample included First Nations, Inuit, and Métis participants from Northwest Territories, Yukon, British Columbia, Saskatchewan, Manitoba, Ontario, Quebec, New Brunswick, and Nova Scotia. A total of 28 people participated in this study. More than 50 per cent of participants were men $(n=18)$. Although valuable data were collected on Indigenous women's experiences of aging, the research team decided to analyze the data separately, given the gendered experiences of both HIV and aging. Sex and gender are recognized as some of the "many social, economic, and environmental factors that determine individual and population health" (Government of Canada, 2018). Beyond biological considerations, "gender norms and roles influence how individuals access health services, and how service providers and health systems respond to them" (Men, Frieson, Socheat, Nirmita, \& Mony, 2011). Men and women experience structural inequities differently, which creates unique vulnerabilities to HIV, and upon diagnosis, men and women experience and access the cascade of care differently. Further, the sociocultural environments that individuals are immersed in have an impact on their exposure to disease and injury, and the resources to which they have access (Public Health Agency of Canada, 2012). The multiple intersecting identities that Indigenous Peoples face based on sex, gender, race, class, ability, and age must be considered. Taking a gendered approach will enable us to identify the unique barriers and needs of these populations. Therefore, this article offers insights on the experiences of aging with HIV from Indigenous men's perspectives, 
while recognizing the need for research on Indigenous women's experiences of aging with HIV as well.

All sharing circles and interviews were audio recorded and transcribed verbatim. A Dropbox folder was created as a secure online space where research team members could review audio recordings and transcripts from the sharing circles and interviews, as well as findings from the literature review. A thematic analytic approach was used to map critical themes in the transcripts, and codes were collaboratively developed by the research team. The analysis was led by a graduate student, as this project was a partial fulfilment of a Master's degree. The analysis involved three stages. Stage one, called open coding, involved, through close analysis, categorizing themes of the data into codes. Stage two, axial coding, referred to the grouping of codes that were related to one another into new categories. In stage three, selective coding identified themes that emerged from the previous two steps. Selective coding is a process that involves "selecting the code category, relating it to other categories, validating those relationships, and filling in categories that need further refinement and development" (Glaser \& Strauss, 2009, p.116). It is from this stage that the spiritual, emotional, mental, social, and physical aspects of health and wellness necessary to age in a good way emerged.

Over several years, a global movement toward the development of Indigenous data sovereignty principles and approaches to data has emerged (Kukutai \& Taylor, 2016), stemming from the self-determination principles outlined in the United Nations Declaration on the Rights of Indigenous Peoples. Briefly, these emerging principles support the need for Indigenous Peoples to govern data about them that are collected and held, as well as to have access and supports to use data for governance (Schnarch, 2004). Principles of Indigenous Data Sovereignty, including OCAP ${ }^{\mathrm{TM}}$ (Ownership, Control, Access and Possession) principles have guided the conception, design, and development of this project. Additionally, this study was approved by the McMaster University Research Ethics Board.

\section{Findings}

From our analysis, five aspects of health and wellness were recognized as essential to First Nations, Inuit, and Métis men's ability to age in a good way with HIV: spiritual, emotional, mental, social, and physical. Participants described a life long journey that one must undergo to age in a good way while living with HIV.

\section{Spiritual}

Participants described the instrumental role that spirituality plays in their ability to age in a good way with HIV. For participants in this study, spirituality typically manifested in one of two ways. For some, their spirituality was innately connected to their Indigeneity, either through learning about their culture and traditions for the first time or through strengthening and/or reconnecting with their cultural and spiritual traditions. For others, their spirituality was independent of their Indigeneity. Regardless of the foundation of an individual's spirituality, the positive impact that spirituality played in these individual's lives was almost tangible.
When I am stressed out, I need to smudge. It makes me feel better...I can't explain it, after you smudge it's like your shoulders just kind of go down (Male, First Nations, Ontario, 43).
That is [sweat lodge] the only way I know to take the stress off and all that stuff that I gather up in society and I can leave that in the lodge when I walk out and let the ancestors take care of it.... When I'm sick, I go to Lakota lodge and it works, I think that's it, for me, its tradition. Tradition is the only reason I am here today and able to keep going and go to school and studying with a brain that's been HIV for 28 years, and then everything else on top of that, you know? (Male, Métis, Nova Scotia, 57).

\begin{abstract}
Understanding that I am a spiritual being and how I can connect with others is really important to me and part of that is through being mindful, using mindful practices, meditation and those things really ground me and make me realize that living in this world is not just about me (Male, First Nations, British Columbia, 53).
\end{abstract}

Although participants did not explicitly state that there was a connection between their spirituality and health, they described how it contributed to their sense of balance, which is an important notion in Indigenous health and wellness. For Indigenous Peoples, spirituality has been described as a resource for "navigating life" and for transcendence (Fleming \& Ledogar, 2008). Participants clearly recognized the important role that spirituality played in their ability to age in a good way. Spirituality helps participants cope with stressors in life, such as their diagnosis of HIV, and it has helped people find meaning in life.

\section{Emotional}

Participants highlighted the importance of emotional wellness to their overall wellness and ability to age in a good way. The importance of self-love, acceptance, and gratitude emerged as prevalent themes in discussions on emotional wellness. Discussions about selflove illustrated a process that many individuals have undertaken or are currently undertaking as a result of their HIV diagnosis. Similar to the idea of self-love were the notions of acceptance and gratitude that also emerged as foundational to emotional wellness. In this study, the notion of acceptance was specific to one's 
identity not only as an Indigenous person but also as a person living with HIV, as many participants have experienced discrimination at some point solely because they are Indigenous and/or HIV positive.

\begin{abstract}
But once I embrace myself and I totally forget about HIV, I don't even know I have HIV anymore. I am just a person who wakes up in the morning and goes out and lives life and other people just don't do that, so you have to, accept, everything before you can embrace and spread the joy to other people (Male, Métis, Ontario, 52).
\end{abstract}

I have realized that I do have a lot of gratitude, this may sound funny to some, but I am grateful to have HIV because I can accept it and also it has made me learn a lot more about my condition, my medications, about all sorts of things, so it has really made me, it has really helped me with that (Male, Native American, British Columbia, 53).

I have had HIV for 22 years and if I could go back and do it again, I wouldn't. I wouldn't change the life I had for the life I have now, friendship in this room, family and everything, wow, it's awesome, and I love it. Thank you, miigwetch (Male, First Nations, Ontario, 43).

Although acceptance is recognized as being a common coping mechanism and stigma management strategy within the HIV and aging literature (Emlet, Tozay, \& Raveis, 2010; Foster \& Gaskins, 2009), a sub-dialogue based on acceptance, which was developed in this study, demonstrated a shift from acceptance to gratitude. Poindexter's (2004) study on six older adults with HIV found that gratitude for life and love was common; however, individuals' gratitude for the disease itself was absent from this discussion. Uniquely, this study found that participants were not only grateful for their lives but also for acquiring HIV. This is because for many participants, their diagnosis was a catalyst for positive change in their lives. Ultimately, self-love, acceptance, and gratitude emerged as imperative to emotional wellness, which materialized as an important criterion of aging in a good way.

\section{Mental}

Within the foundational model of successful aging, discussions around mental health are often limited to maintaining high levels of cognitive functioning, whereas in this study discussions around mental health and wellness were in relation to abstaining from drugs and alcohol, finding purpose in life, and gaining control of one's life. Participants described abstaining from drugs and alcohol to achieve a clear mind as an important part of their mental health and wellness. Finding a purpose in life was particularly important for participants given the recent reality of being able to live into old age with HIV. As is the case for many older adults with HIV, participants spoke about the fact that they never thought that they would live into their old age. "I never thought I would hit 30, I never believed I'd hit 40 and 50 I was like oh my god 60 is coming and sometimes the realization scares me" (Male, Métis, Ontario, 57). Consequently, many older adults with HIV did not make plans for their future, as they did not think they would have a future. Now that these individuals are starting to accept the fact that they could now die in old age, they are recognizing the need to find new purpose in life. Additionally, individuals spoke about the importance of control and self-determination to their mental health and wellness. Self-determination is becoming increasingly recognized as an important determinant of health and wellness (Reading \& Wien, 2009).

I realized, I have a 12-year-old [dog] and when I walk him down to the beach the last time I went into recovery I walked him down to the beach and I watched him jump into the water and he'd come out and he'd shake it all off and I went, that's what crack does to me! [Laughing] shake it all off, right, and so now I have had to find healthier ways to shake it all off! (Male, Métis, Ontario, 57).

I need to figure that out now that I am living longer what am I going to do with my life? Because before it was sort of like, you're on disability you have an income, you're getting sick [and] the end result is you're going to die. Well, now that the medications are working better, people are being more smart about what they are doing, they are living way longer. So, what do I - how do I - you know like everybody needs, has their own journey and their own path. Well if it's going to be a lot longer what do you do in that time? (Male, First Nations, Ontario, 50).

Also for me, successful aging is really listening to my body and going to a doctor when I need to and going there with knowledgeable questions and not just taking their answers because sometimes the doctors may not know what they are doing and having to question them and be willing to fire a doctor, because I have fired a doctor and gone to other doctors because I felt that I wasn't getting my needs met by that particular doctor. So part of that means being engaged in my own health care (Male, First Nations, British Columbia, 53).

The significance of drugs and alcohol on a participant's mental wellness is not surprising given that drugs and alcohol are frequently used by people experiencing illness, trauma, and pain as a way to cope. Alcohol abuse has a profound impact on an individual's ability to function (Reading \& Wien, 2009). By taking control over their health care and ultimately their lives, these individuals are demonstrating mastery. A study on protective risk factors associated with HIV stigma found 
mastery to be instrumental in minimizing HIV-related stigma in a population of older HIV positive adults in Ontario, Canada (Emlet et al., 2013). In this study, although participants did not directly articulate how abstaining from drugs and alcohol and achieving a sense of purpose, control, self-determination, and mastery improved their mental wellness, they did see these factors as being important to their ability to age in a good way (i.e., Mino-Bimaadiziwin).

\section{Physical}

Although the importance of physical functioning is central to foundational models of successful aging, participants in this research tended to place less emphasis on their physical health than they did on the spiritual, mental, emotional, and social aspects of health and wellness. Furthermore, foundational models of successful aging require an absence of disease and disability, therefore automatically excluding older HIV positive individuals from qualifying as successful agers. However, participants in this study did not see the fact that they are living with a chronic, potentially life-threatening disease as well as several other co-morbidities as an impediment to successful aging. Rather, when physical health was discussed it was typically in relation to treating one's physical body well through maintaining a well-balanced diet, engaging in physical activity, adhering to medications, and using drugs and alcohol in moderation.

Living healthy and taking care of yourself. Aging with $\mathrm{HIV}$ is kind of going with it and taking care of yourself, medication wise, eating wise, exercise, rest, stuff like that. (Male, Métis, Manitoba, 58).

I don't know, I'm really - like I've been positive for 22 years and I am really healthy, I just had a visit with my doctor and yet I go on these alcohol binges and drug binges once in a while and I just don't get it, why, you know? (Male, First Nations, Manitoba, 51).

Although many participants did discuss the connection between maintaining good physical health to their ability to age in a good way, many were not able to separate their physical health from their overall health and wellness.

\section{Social}

Engaging in social situations and maintaining social ties emerged as being instrumental to participants' spiritual, emotional, mental, and physical health and wellness. Participants highlighted the positive impact that engaging with others had on their overall health and wellness. Engagement with others provided opportunities for individuals to learn from, teach, and share one another's experiences. Most individuals' experiences involving social engagement and their explanations about how social cohesion positively impacted their wellness demonstrated opportunities in which they could not only receive support but also provide support. Therefore, discussions on social engagement can be organized into two categories:

\section{Opportunities for Social Support (Learn and Share)}

I think to, learn from other people, like right here, most of the stuff that we are talking about, I think all of us feel, because we have been there somewhere at some point. And everybody thinks that you're alone but you're not, I mean I always think my life was tough but listening to other people's like I'm grateful (Male, Métis, New Brunswick, 52).

I'm just so grateful to be here like physically at this CAAN event because my tank was empty, right, and to get here and to see everybody else wherever they are at, right, I remember when I was there, I remember when I felt that, I remember when I hated that, right, and um, it's amazing once I stopped hating myself how much I could love other people (Male, Métis, Ontario, 57).

\section{Opportunities to Provide Social Support (Teach and Share)}

I mean I sit on very many, many community committees, provincially and nationally and that keeps me going, you know, it energizes me... the creator says you're not going anywhere, you've got work to be done and you need to stick around to help others and teach others (Male, First Nations, British Columbia, 55).

So after I lost him I thought what am I going to do with myself? So that's when I started thinking, maybe I should start participating in these HIV programs and so I started participating and going to these conferences in_and then I started enjoying them so I asked if I could go to the ones out of town and my band started supporting me, I did a couple of presentations on HIV on the reserve, when I was living on the reserve because they wanted to let everybody know what HIV and one just a couple of years ago because they paid for me to go to a couple of conferences, so I went and did one a couple of years ago, so it was alright, I'm glad I got to tell my story, the way I grew up and stuff, I even got involved in gangs and stuff like that, but I put all of that behind me about 13 years ago and now I just want to continue on my journey for the rest of my life with helping other HIV + people and um, sharing my stories. I am just glad to be here (Male, First Nations, Manitoba, 51).

I go out to the schools in ___ the reserves around the area and I teach them about what it is like to live with HIV and I am always concerned about the younger generations. How are they going to, how are they going to handle their diagnosis? Or are they going to go to- who are they going to see. I think a lot of us think of our parents, when we are that age, we want to run to our parents. Some of us just 
don't have that, we don't have our mom and dads. But I think of them and I really, try to teach them to be cautious, you know, think twice before them, before they get into a high risk, you know, situation, to really stop and think (Male, Inuk, British Columbia, 53).

These quotes demonstrate the importance of social relationships that provide opportunities for individuals to learn from their peers who are also HIV positive, as well as from community resources and organizations such as CAAN. This connects to a lived experience of Indigenous ontologies, demonstrating the importance that Indigenous Peoples place on passing knowledge on to others as a way of contributing not only to one's own health and wellness, but also to community health and wellness. Additionally, these quotes demonstrate the significance of social opportunities that provide individuals with an outlet to teach others. These participants highlight the purpose and direction that being able to teach others about HIV gives them in life. Furthermore, opportunities to teach and share contributed to an individual's purpose in life and mastery, which is positively associated with better emotional and mental health outcomes. Much of the discussion on social engagement centered on an obligation that many individuals felt to share their life stories to teach others about HIV, with the goal of reducing its impact on their communities. Ultimately, social engagement, whether it took the form of learning, sharing, or teaching, proved to be a fundamental component of one's ability to age in a good way.

\section{Aging in a Good Way}

Throughout this study, a measurable and testable model of successful aging did not evolve. Instead, what emerged were five aspects (spiritual, emotional, mental, physical, and social) of health and wellness that participants felt were necessary to nurture in order to age in a good way. Unlike foundational models of successful aging, participants did not dichotomize themselves or others as being either successful or unsuccessful. Rather, in performing their masculine identities (Innes \& Anderson, 2015), participants elucidated relational journeys that they are undertaking to age in a good way. These journeys highlighted the strengths and cultural assets that contribute to aging in a good way, rather than focusing on the challenges and deficits commonly associated with HIV and aging. As an alternative to proposing an Indigenous model of successful aging, recognizing the complexity and potential harms associated with doing so, we want to share these experiences of aging in a good way for others to learn from. Recognizing that everyone is at a different starting place, we offer these narratives as an alternative to a successful aging framework. This resonates with Indigenous world-views, which are experiential, flexible, and accepting.

\section{Limitations}

It is important to note that not all participants were over the age of 50. Although this was initially required as one of the inclusion criteria, we decided to allow individuals under the age of 50 to participate for a few reasons. For the sharing circle with men, two men under the age of 50 made the case that they too were aging with HIV, and they wanted the opportunity to learn from their peers about how to "age successfully" with HIV/AIDS. Like our decision to allow interviews, we wanted to be flexible and inclusive in our research approach. Furthermore, the research team thought that turning people away would be counter-intuitive to our decolonizing research approach, given that this type of approach is about recognizing the traditional power imbalances that exist within research, and working to eradicate such imbalances. Additionally, it is important to point out that although this article describes an exploratory study of Indigenous People's experiences with HIV, the participants were predominantly First Nations and Métis, and there is limited representation of Inuit. Because of a relatively small sample size, separate analyses were not completed for First Nations, Inuit, and Métis, geographic representation, or sexual orientation.

\section{Discussion}

What we learned from this sample of older First Nations, Inuit, and Métis men aging with HIV is that these individuals did not dichotomize themselves or others into "successful" and "unsuccessful" agers. Male participants did not equate challenges such as having HIV, mobility constraints, the loss of a limb, low income, addictions, or lack of employment as factors that disqualified them or someone else from being able to age successfully. Rather, these individuals focused on their strengths and things that they were gaining such as clarity, wisdom, improved relationships with family and friends, spiritual and cultural knowledge, resilience, purpose, direction in life, and self-determination as factors that contributed to their ability to age successfully, or rather, in a good way (i.e., Mino-Bimaadiziwin or living the way of a good life).

This observation supports our view that the biomedical bias and ableism inherent in the Rowe and Kahn model of successful aging obscures the abilities of Indigenous People living with HIV to successfully adapt to the challenges associated with aging with a chronic and disabling illness. Perhaps this distinction is the result of differences in beliefs about aging between Indigenous and Western cultures, such as the differences in perspectives of health and wellness. Western culture has become obsessed with prolonging youth and thereby delaying death, whereas many Indigenous Peoples take 
pleasure in aging because old age represents a time when one is held in high esteem. Furthermore, the older years are commonly understood as a time when individuals can pass on their life experiences (GeorgeKanentiio, 2000).

Although Rowe and Kahn's (1997) successful aging framework represents a normative ideal, it lacks consideration of macro social structural conditions (Martinson \& Berridge, 2015). Foremost among the socio-structural conditions that shape male Indigenous experience is colonization. An Indigenous process of aging in a good way, as outlined in this research, considers these macro social structural conditions as well as cultural factors of aging that this population experiences, allowing for "success" regardless of one's sociocultural location. Indigenous men aging with HIV resist the colonial imposition and have clearly articulated some distinct needs and priorities that are not well represented in Rowe and Kahn's (1997) model of successful aging. As a result, and largely because there is little Indigenous literature on the topic of aging with HIV, we know little about how masculine Indigenous identity is negatively shaped and experienced as both gendered and racial discrimination (Innes \& Anderson, 2015). In the case of Indigenous populations, "successful aging takes place at the intersection of individual, social, and cultural contexts across the life course, and against particular historical, economic, and political backdrops" (Pace \& Grenier, 2017, p. 250). Where the foundational models of successful aging strive to be measurable and testable based on individual measures, this may not be appropriate for Indigenous Peoples, and further, could be harmful. Focusing instead on aging in a good way is reflective of Indigenous ways of knowing and leaves room for differences within and among First Nations, Inuit, and Métis peoples, languages, cultures, traditions, and beliefs. Central to these Indigenous People's abilities to age in a good way Mino-Bimaadiziwin - is finding a balance within the spiritual, emotional, mental, physical, and social aspects of their health and wellness. In this respect, emerging from our data in ways consistent with Anderson, Swift, \& Innes (2015), a positive masculine identity is lived in the context of roles and responsibilities (i.e., to share and give back to community), culture (i.e., learning about Indigenous traditions and protocols), and relationships to one's self, community, and nation, all of which are tethered to the broader Indigenous community project to revitalize Indigenous culture. Aging in a good way thus illustrates a journey of holistically healing oneself, rather than a harmful path of trying to achieve normative ideals of aging that are often unrealistic if not completely unattainable.

Participants' emphasis on gains and cultural assets has service and practice implications that need to be considered. Although most evidence-based HIV-related programs used by Indigenous men are often shaped by Western perspectives (Hodge, Limb, \& Cross, 2009), effective HIV-related programs and services should build on Indigenous men's strengths, embedding cultural knowledge and assets within program and service design and delivery (Peltier et al., 2013). HIV-related programs and more broadly, all health and social services and supports for Indigenous men with and without HIV need to be designed with Indigenous men with and without HIV. Given their different lived realities and the differing perspectives on aging with HIV and health and wellness more broadly, mainstream services that do not culturally resonate will continue to lack success. Programs and services that aim to promote successful aging within this population will not be successful until successful aging is understood in the context of colonization and systemic racism. It is within this context that we must consider successful aging for this population, and, therefore, successful aging for Indigenous Peoples must take a decolonizing approach.

\section{Conclusion}

Although more literature is needed on aging with HIV / AIDS and greater consideration of successful aging with HIV/AIDS is needed, specifically through Indigenous lenses, we need to acknowledge that there is no one ideal way of aging between cultures, or even within cultures. Martinson and Berridge (2015) suggest that creating ideal models of aging is destructive and serves to devalue the diversity in views on aging. Therefore, rather than proposing the development of an Indigenous model of successful aging, we share our insights on aging in a good way based on the narratives of Indigenous men aging with HIV. Given that Indigenous perspectives of successful aging, or more appropriately, aging in a good way, shared in this project do not describe an unattainable ideal of aging or suggest a need to measure and test individuals' abilities to age successfully, this idea should not contribute to the further harm and marginalization of older Indigenous Peoples. Alternatively, these narratives offer an opportunity to meet other Indigenous Peoples living with HIV where they are, providing them with examples based on strengths and cultural assets to help them age in a good way. Aging in a good way should be viewed as a lifelong, relational journey. This journey is about resiliency, healing, and empowerment, and if presented this way, leaves little room for harm.

For Indigenous men living with HIV to age in a good way, children, women, community leaders, and Elders must be involved in the design and delivery of HIV programs and services (Peltier et al., 2013). This community-wide involvement will contribute to 
collective as well as individual healing and "healing from this perspective attends to the notion of relational connection and invites and cultivates a mutually supportive environment in which health and wellbeing are fostered and maintained" (Peltier et al., 2013, p. 94). Offering alternatives to successful aging models and normative ideals of aging rooted in Indigenous knowledge systems is an important step to de-colonizing the field of social gerontology and Western evidencebased approaches to HIV programs and services. De-colonization is foundational to Indigenous health and wellness and, therefore, Indigenous People's abilities to age in a good way. Ultimately, this research offers a de-colonizing approach to successful aging, in which one's ability to age in a good way, despite living with HIV, is far more attainable than in traditional models of successful aging.

\section{References}

Adelson, N. (2005). The embodiment of inequity: Health disparities in Aboriginal Canada. Canadian Journal of Public Health/ Revue Canadienne de Sante'e Publique, 96(S2), S45-S61.

Anderson, K., Swift, J., \& Innes, R. A. (2015). “To arrive speaking": Voices from the Bidwewidam Indigenous masculinities project. In R. A. Innes \& K. Anderson (Eds.), Indigenous men and masculinities: Legacies, identities, and regeneration (pp. 283-307). Winnipeg, MB: University of Manitoba Press.

Balderson, B. H., Grothaus, L., Harrison, R. G., McCoy, K., Mahoney, C., \& Catz, S. (2013). Chronic illness burden and quality of life in an aging HIV population. AIDS Care, 25(4), 451-458.

Bartlett, C., Marshall, M., \& Marshall, A. (2012). Two-eyed seeing and other lessons learned within a co-learning journey of bringing together indigenous and mainstream knowledges and ways of knowing. Journal of Environmental Studies and Sciences, 2(4), 331-340.

Benoit, A. C., Younger, J., Beaver, K., Jackson, R., Loutfy, M., Masching, R., et al. (2017). Increased mortality among Indigenous persons in a multisite cohort of people living with HIV in Canada. Canadian Journal of Public Health, 108(2), 169-175.

Beuthin, R. E., Bruce, A., \& Sheilds, L. (2015). Storylines of aging with HIV shifts toward sense making. Qualitative Health Research, 25(5), 612-621.

Brennan, D. J., Emlet, C. A., Brennenstuhl, S., Rueda, S., \& OHTN Cohort Study Research Team and Staff. (2013). Socio-demographic profile of older adults with HIV/ AIDS: Gender and sexual orientation differences. Canadian Journal on Aging/La Revue canadienne du vieillissement, 32(1), 31-43.

Cahill, S., \& Valadéz, R. (2013). Growing older with HIV / AIDS: New public health challenges. American Journal of Public Health, 103(3), e7-e15.
Cammer, A. L. (2006). Negotiating Culturally Incongruent Healthcare Systems: The Process of Accessing Dementia Care in Northern Saskatchewan (Doctoral dissertation). Retrieved 25 September 2017 from http:/ / citeseerx.ist. psu.edu/viewdoc/download?doi=10.1.1.826.2265\&rep= rep $1 \&$ type $=$ pdf

Deeks, S. G., \& Phillips, A. N. (2009). HIV infection, antiretroviral treatment, ageing, and non-AIDS related morbidity. British Medical Journal, 338(a3172), 288-292.

Douglas, V. (2013). Introduction to Aboriginal health and health care in Canada. New York: Springer.

Ellman, T. M., Sexton, M. E., Warshafsky, D., Sobieszczyk, M. E., \& Morrison, E. A. (2014). A forgotten population: Older adults with newly diagnosed HIV. AIDS Patient Care and STDs, 28(10), 530-536.

Emlet, C. A., Brennan, D. J., Brennenstuhl, S., Rueda, S., Hart, T. A., Rourke, S. B., et al. (2013). Protective and risk factors associated with stigma in a population of older adults living with HIV in Ontario, Canada. AIDS Care, 25(10), 1330-1339.

Emlet, C. A., Tozay, S., \& Raveis, V. H. (2010). “I'm not going to die from the AIDS": Resilience in aging with HIV disease. The Gerontologist, 51(1), 101-111.

Fleming, J., \& Ledogar, R. J. (2008). Resilience, an evolving concept: A review of literature relevant to Aboriginal research. Pimatisiwin, 6(2), 7-23.

Foster, P. P., \& Gaskins, S. W. (2009). Older African Americans' management of HIV/AIDS stigma. AIDS Care, 21(10), 1306-1312.

George-Kanentiio, D. (2000). Iroquois culture and commentary. Santa Fe, NM: Clear Light Publishers.

Glaser, B. G., \& Strauss, A.L. (2009). The discovery of grounded theory: Strategies for qualitative research. Chicago: Aldine Transaction.

Government of Canada. (2018). Social determinants of health and health inequalities. Health science, research and data. Retrieved 25 September 2017 from https:/ / www.canada. ca/en / public-health/services / health-promotion / population-health/what-determines-health.html

Health Council of Canada. (2013). Canada's most vulnerable: Improving health care for First Nations, Inuit, and Métis seniors. Toronto: Author.

Henry, R., Tait, C., \& STR8, UP. (2016). Creating ethical research partnerships-Relational accountability in action. Engaged Scholar Journal: Community-Engaged Research, Teaching and Learning, 2(1), 183-204.

Hodge, D., Limb, G., \& Cross, T. (2009). Moving from colonization toward balance and harmony: A Native American perspective on wellness. Social Work, 54(3), 211-219.

Hughes, M. L. (2006). Critical incident stress debriefing as a trauma intervention in First Nation Communities. Canadian Journal of Counselling, 40(2), 82-95. 
Innes, R. A., \& Anderson, K. (2015). Who's walking with our brothers. In R.A. Innes \& K. Anderson (Eds.), Indigenous men and masculinities: Legacies, identities, regeneration (pp. 3-17). Winnipeg, MB: University of Manitoba Press.

King, M., Smith, A., \& Gracey, M. (2009). Indigenous health part 2: The underlying causes of the health gap. The Lancet, 374(9683), 76-85.

Kukutai, T., \& Taylor, J. (2016). Indigenous data sovereignty: Towards an agenda. Acton, Australia: ANU Press.

Lavallée, L. F. (2009). Practical application of an Indigenous research framework and two qualitative Indigenous research methods: Sharing circles and Anishnaabe symbol-based reflection. International Journal of Qualitative Methods, 8(1), 21-40.

Liang, J., \& Luo, B. (2012). Toward a discourse shift in social gerontology: From successful aging to harmonious aging. Journal of Aging Studies, 26(3), 327-334.

Martin, P., Kelly, N., Kahana, B., Kahana, E., Willcox, B. J., Willcox, D. C., et al. (2014). Defining successful aging: A tangible or elusive concept? The Gerontologist, 55(1), 14-25.

Martinson, M., \& Berridge, C. (2015). Successful aging and its discontents: A systematic review of the social gerontology literature. The Gerontologist, 55(1), 58-69.

Men, C.R., Frieson, K., Socheat, C., Nirmita, H., \& Mony, C. (2011). Gender as a social determinant of health: Gender analysis of the health sector in Cambodia. World conference on social determinants of health. Retrieved 26 February 2018 from http:/ /www.who.int/sdhconference/resources/ draft_background_paper15_cambodia.pdf

Nevedal, A., \& Sankar, A. (2015). The significance of sexuality and intimacy in the lives of older African Americans with HIV/AIDS. The Gerontologist, 56(4), 762-771.

Pace, J. E., \& Grenier, A. (2017). Expanding the circle of knowledge: Reconceptualizing successful aging among North American older Indigenous peoples. The Journals of Gerontology, 72(2), 248-258.

Peltier, C. (2018). An application of two-eyed seeing: Indigenous research methods with participatory action research. International Journal of Qualitative Methods, 17(1), $1-12$.

Peltier, D., Jackson, R., Prentice, T., Masching, R., Monette, L., Fong, M., et al. (2013). When women pick up their bundles: HIV prevention and related service needs of Aboriginal women in Canada. In J. Gahagan (Ed.), Women and HIV prevention in Canada (pp. 85-103). Toronto: Canadian Scholars' Press.
Poindexter, C. C. (2004). Six champions speak about being over 50 and living with HIV. Journal of HIV/AIDS \& Social Services, 3(1), 99-117.

Public Health Agency of Canada. (2012). Chapter 2: The Chief Public Health Officer's report on the state of public health in Canada 2012 - Sex, gender and public health. Retrieved 25 February 2018 from https: / /www. canada.ca/en/public-health/corporate/publications / chief-public-health-officer-reports-state-public-healthcanada/chief-public-health-officer-report-on-state-publichealth-canada-2012/chapter-2.html

Public Health Agency of Canada. (2014). HIV/AIDS Epi Updates Chapter 8: HIV/AIDS among Aboriginal people in Canada. Ottawa: Author.

Reading, C. L., \& Wien, F. (2009). Health inequalities and the social determinants of Aboriginal peoples' health. Prince George, BC: National Collaborating Centre for Aboriginal Health.

Roger, K. S., Mignone, J., \& Kirkland, S. (2013). Social aspects of HIV/AIDS and aging: A thematic review. Canadian Journal on Aging/La Revue canadienne du vieillissement, 32(3), 298-306.

Rothe, J. P., Ozegovic, D., \& Carroll, L. J. (2009). Innovation in qualitative interviews: "Sharing Circles" in a First Nations community. Injury Prevention, 15(5), 334-340.

Rowe, J. W., \& Kahn, R. L. (1997). Successful aging. The Gerontologist, 37(4), 433-440.

Saks, M., \& Allsop, J. (2007). Researching health: Qualitative, quantitative, and mixed methods. London: Sage.

Sankar, A., Nevedal, A., Neufeld, S., Berry, R., \& Luborsky, M. (2011). What do we know about older adults and HIV? A review of social and behavioral literature. AIDS Care, 23(10), 1187-1207.

Schnarch, B. (2004). Ownership, control, access, and possession (OCAP) or self-determination applied to research: A critical analysis of contemporary First Nations research and some options for First Nations communities. International Journal of Indigenous Health, 1(1), 80-95.

Smith, L. T. (1999). Decolonizing methodologies: Research and Indigenous peoples. London, New York, Dunedin: Zed Books; University of Otago Books.

Vance, D. E., Struzick, T. C., \& Masten, J. (2008). Hardiness, successful aging, and HIV: Implications for social work. Journal of Gerontological Social Work, 51(3-4), 260-283.

Wilson, S. (2008). Research is ceremony: Indigenous research methods. Winnipeg, MB: Fernwood Publishing Co. 